\title{
Brain state-dependent abnormal LFP activity in the auditory cortex of a schizophrenia mouse model
}

\author{
Kazuhito Nakao ${ }^{1,2}$ and Kazu Nakazawa ${ }^{1,2}$ * \\ ${ }^{1}$ Department of Psychiatry and Behavioral Neurobiology, University of Alabama at Birmingham, Birmingham, AL, USA \\ 2 Unit on Genetics of Cognition and Behavior, Department of Health and Human Services, National Institute of Mental Health, National Institutes of Health, \\ Bethesda, MD, USA
}

Edited by:

Yukiko Kikuchi, Newcastle University Medical School, UK

Reviewed by:

Piia Astikainen, University of Jyväskylä, Finland

Huan Luo, Chinese Academy of

Sciences, China

\section{*Correspondence:}

Kazu Nakazawa, Department of

Psychiatry and Behavioral

Neurobiology, University of Alabama

at Birmingham, Shelby Building

1105, 1825 University Boulevard,

Birmingham, AL 35294, USA

e-mail:nakazawk@uab.edu
In schizophrenia, evoked $40-\mathrm{Hz}$ auditory steady-state responses (ASSRs) are impaired, which reflects the sensory deficits in this disorder, and baseline spontaneous oscillatory activity also appears to be abnormal. It has been debated whether the evoked ASSR impairments are due to the possible increase in baseline power. GABAergic interneuron-specific NMDA receptor (NMDAR) hypofunction mutant mice mimic some behavioral and pathophysiological aspects of schizophrenia. To determine the presence and extent of sensory deficits in these mutant mice, we recorded spontaneous local field potential (LFP) activity and its click-train evoked ASSRs from primary auditory cortex of awake, head-restrained mice. Baseline spontaneous LFP power in the pre-stimulus period before application of the first click trains was augmented at a wide range of frequencies. However, when repetitive ASSR stimuli were presented every $20 \mathrm{~s}$, averaged spontaneous LFP power amplitudes during the inter-ASSR stimulus intervals in the mutant mice became indistinguishable from the levels of control mice. Nonetheless, the evoked $40-\mathrm{Hz}$ ASSR power and their phase locking to click trains were robustly impaired in the mutants, although the evoked $20-\mathrm{Hz}$ ASSRs were also somewhat diminished. These results suggested that NMDAR hypofunction in cortical GABAergic neurons confers two brain state-dependent LFP abnormalities in the auditory cortex; (1) a broadband increase in spontaneous LFP power in the absence of external inputs, and (2) a robust deficit in the evoked ASSR power and its phase-locking despite of normal baseline LFP power magnitude during the repetitive auditory stimuli. The "paradoxically" high spontaneous LFP activity of the primary auditory cortex in the absence of external stimuli may possibly contribute to the emergence of schizophrenia-related aberrant auditory perception.

Keywords: auditory steady-state responses, GABAergic interneurons, gamma oscillation, local field potentials, NMDA receptors, parvalbumin, schizophrenia, mouse models

\section{INTRODUCTION}

Neural oscillation and synchronization abnormalities have been suggested to play a role in the information and sensory processing deficits commonly seen in schizophrenia (Ford and Mathalon, 2008; Uhlhaas and Singer, 2010; Gandal et al., 2012a). Periodic auditory stimulation entrains the electro-encephalogram (EEG) to a specific phase and frequency, often referred to as the auditory steady-state response (ASSR). In both human and animal models, the ASSR has been used to assess the functional integrity of neural circuits that support synchronization (Picton et al., 2003; Brenner et al., 2009; O’Donnell et al., 2013). In schizophrenia, reduced ASSR power (magnitude) and phase locking (phase consistency across trials), particularly at $40 \mathrm{~Hz}$, are observed in EEG (Kwon et al., 1999; Brenner et al., 2003; Light et al., 2006; Spencer et al., 2008, 2009; Vierling-Claassen et al., 2008; Krishnan et al., 2009) as well as in magneto-encephalogram (MEG) (Teale et al., 2008; Maharajh et al., 2010; Tsuchimoto et al., 2011) studies. Since cortical parvalbumin (PV)-positive fast-spiking interneurons have an intrinsic resonance near this range (Tateno et al., 2004; Golomb et al., 2007), the reduction in $40-\mathrm{Hz}$ ASSRs may reflect functional deficits of these fast-spiking neurons in schizophrenia.

Earlier studies of gamma synchrony deficits in schizophrenia reported the relative changes in gamma band activity in response to task stimuli, by assessing stimulus-evoked responses in synchrony compared with a pre-stimulus baseline (Kwon et al., 1999; Haig et al., 2000; Lee et al., 2003). Thus, in these studies relatively less evoked gamma synchrony could be a reflection of greater baseline spontaneous gamma phase synchrony under pre-stimulus conditions. However, in schizophrenia the evidence regarding baseline gamma activity abnormalities is inconsistent. Both increases (Jalili et al., 2007; Venables et al., 2009; Kikuchi et al., 2011; Spencer, 2012) and decreases (Yeragani et al., 2006; Rutter et al., 2009) in baseline spontaneous gamma power during pre-stimulus period or "resting state" have been reported. The reason for these contradictory results has yet to be clarified.

To measure the baseline spontaneous gamma band power with high precision, it would be useful to directly record local field potentials (LFPs), necessitating the use of animal models. To that end, we recorded LFPs directly from the primary auditory 
(A1) cortex of GABAergic interneuron-specific NMDA receptor (NMDAR) hypofunction mice (Ppp1r2-cre/fGluN1 KO mice). Previous studies using this mutant mouse revealed that the selective deletion of GluN1, an indispensable subunit of NMDARs, in cortical and hippocampal interneurons during early postnatal development recapitulates several schizophrenia-like behavioral and pathophysiological phenotypes (Belforte et al., 2010; Jiang et al., 2013). In the present study, we subjected these mutant mice to the ASSR paradigm, similar to the one used in human studies (Krishnan et al., 2009). We assessed the auditory click trainevoked ASSRs and baseline LFP fluctuations in pre/post-stimulus period and at baseline (i.e., between stimulus presentations).

\section{MATERIALS AND METHODS}

All experimental procedures were in accordance with National Research Council guidelines for the care and use of laboratory animals, and were approved by the National Institute of Mental Health Animal Care and Use Committee. Data analysis was conducted at the University of Alabama at Birmingham.

\begin{abstract}
ANIMAL
Ppp1r2-cre ${ }^{(+/-)} / \mathrm{fGluN1}^{(\mathrm{f} / \mathrm{f})}$ mice (henceforth referred to as $\mathrm{KO}$ mice or mutants) were generated as previously described (Belforte et al., 2010). Briefly, the protein phosphatase 1, regulatory subunit 2 (Ppp1r2)-cre line and a floxed-GluN1 (fGluN1) line were used to delete exons 9 and 10 of GluN1 gene from the postnatal second week in a subset of cortical and hippocampal Ppp1r2-cre positive interneurons, the majority of which are PV-positive. Female mutant mice were bred to homozygously fGluN1 male mice to generate the same mutant and fGluN1 control mice with a $50 \%$ probability. In the present study, 65 male mice received chronic survival surgery for the microwire array implantation. After successful detection of the auditory-evoked potentials 1 week after the surgery, 7 fGluN1 control (13-16 week-old, $30.6 \pm 0.65 \mathrm{~g}$ body weight) and 6 mutant (12-14 week-old, $28.1 \pm 0.8 \mathrm{~g})$ mice were subjected to in-depth analysis of ASSRs, as described in Result section.
\end{abstract}

\section{SURGICAL PROCEDURES}

Animals were anesthetized with isoflurane to surgical levels and were mounted in a stereotaxic instrument with non-rupture ear bars (Zygoma ear cups, David Kopf Instruments). A custommade plastic headpost was secured to the occipital bone at the midline with superglue and dental acrylic, and was used to fix the animal's skull to the stereotaxic instrument. This was done to prevent physical occlusion of the external ear canals by stereotaxic ear bars in order to obtain tone-evoked LFP responses. A unilateral craniotomy was made over the right temporal bone from 1.5 to $3.5 \mathrm{~mm}$ posterior to bregma and from 3.5 to $4.5 \mathrm{~mm}$ lateral to midline. The vasculature was inspected. The microwire multielectrode array consisted of six tetrodes, which were customconfigured in a $2 \times 3$ matrix with inter-electrode distance of $\sim 200 \mu \mathrm{m}$, covering $0.6 \times 0.8 \mathrm{~mm}^{2}$. The impedance of each electrode was between 0.2 and $0.3 \mathrm{M} \Omega$. The microwire array was inserted into the superficial layers of Al cortex with the aid of cortical vascular patterns, and two stainless steel screws in the frontal cortex which served as ground and reference electrodes. After the dosage of isoflurane was reduced to $1 \%$, a single white noise pulse ( $1 \mathrm{~ms}$, duration; $80 \mathrm{~dB}, \mathrm{SPL}$ ) was applied to activate the A1 corti$\mathrm{cal}$ area. In order to allow for the tone-evoke responses it is critical to maintain the isoflurane concentration at $1 \%$ (Santarelli et al., 2003). The animal was held in place with adhesive tape to prevent head twitching or grooming. An analgesia (buprenorphine, $0.1 \mathrm{mg} / \mathrm{kg}$ s.c.) was given to diminish pain sensation during the surgery. If single-tone evoked potentials (over $0.1 \mathrm{mV}$ magnitude) were detected in at least one electrode of the microwire array, the electrodes were inserted further until maximal responses were obtained. The anesthetic dose was then returned back to surgical levels, and the microwire array was fixed to the skull with dental acrylic.

\section{IN VIVO RECORDING}

Seven days after surgery, LFP recording was performed from A1 cortex of awake, head-restrained mice. The mice were briefly anesthetized with $1 \%$ isoflurane to hold the animal head fixed to the stereotaxic instrument using the headpost, and the body was covered with adhesive paper tape to limit body movements. The micro-array electrodes were directly connected, via an EIB-27Micro headstage pre-amplifier, to a Cheetah-64 recording system (Neuralynx Inc.), where LFP signals were filtered (bandwidth from 0.1 to $475 \mathrm{~Hz}$ ), digitized, and acquired at a sampling rate of $1.56 \mathrm{kHz}$ per channel. Thirty minutes after the cessation of anesthesia, LFP recording began from Al cortex of awake, headrestrained mice in a custom-made auditory isolation chamber (background sound level, $40 \mathrm{~dB}$ SPL).

In the first session, spontaneous LFP activity during a prestimulus period was recorded from A1 cortex for 2-25 min. Subsequently, in the second session, 500-ms long click trains consisting of $80 \mathrm{~dB}$ white-noise pulses presented at $40 \mathrm{~Hz}(40-$ $\mathrm{Hz}$ ASSR stimuli) were applied 50 times with an inter-stimulus interval of $20 \mathrm{~s}$, which mimics the ASSR protocol used in human studies (Krishnan et al., 2009). Auditory click stimuli, consisting of white noise pulses ( $1 \mathrm{~ms}$, duration; $80 \mathrm{~dB}$, SPL), were generated in Labview (National Instruments Inc.), and presented using a speaker with a $35 \mathrm{~Hz}-20 \mathrm{kHz}$ frequency response (Z3, Logitech Inc.) placed $30 \mathrm{~cm}$ above the mouse head. In the third session, which began $10 \mathrm{~min}$ after cessation of the second session, 1000ms long click trains consisting of $80 \mathrm{~dB}$ white-noise presented at $20 \mathrm{~Hz}$ (20-Hz ASSR stimuli) were applied 50 times with an interstimulus interval of $20 \mathrm{~s}$. In the last session, spontaneous LFP activity was recorded for $25 \mathrm{~min}$ as a post-stimulus period. When no auditory evoked LFP responses were detected in any channels during the second session, the experiment was terminated and the animal was euthanized.

\section{LFP ANALYSIS}

Only the channel data in which the amplitude of initial N1 response in the $40 \mathrm{~Hz}$-ASSRs was more than $0.1 \mathrm{mV}(\sim 4$ times the standard deviation), were used for subsequent analyses. Neuralynx LFP files were first converted to Spike2 format to visually inspect the raw data. Next, LFP voltage values in the Neuralynx files were converted to Matlab (Mathworks) files, and these values were normalized to the $\mathrm{z}$-scores by subtracting the mean and dividing by the standard deviation of the LFP 
voltages during entire recording epoch $(\sim 20 \mathrm{~min})$. The Matlab files with the $\mathrm{z}$-scores were then converted to NeuroExplorer (Nex Technologies) files to calculate the power.

In order to assess the oscillatory component of evoked ASSRs, z-score normalized LFPs during the last 200-ms of each ASSR were analyzed with a fast Fourier transform (FFT) algorithm in the range of $0-100 \mathrm{~Hz}$ using 256 frequency bins and presented as total ASSR power (e.g., Figure 1C). Relative power amplitudes were calculated by subtracting a baseline spontaneous power, which was from the 200 -ms inter-stimulus segment $10 \mathrm{~s}$ prior to each click-train onset, from the total ASSR power (see Figure 1E).

For spontaneous LFP power during a pre-stimulus period, LFP data (200-ms bin) during the last $10 \mathrm{~s}$ prior to the first click-train administration were analyzed with FFT algorithm in the range of $0-200 \mathrm{~Hz}$ using 256 frequency bins (Figure 3). To compare the baseline power magnitudes in-between ASSR sessions with the spontaneous power during the pre- or post-stimulus period, z-score normalized LFP from 5 to $15 \mathrm{~s}$ (200-ms bin) after 1 st stimuli, 25th stimuli, and 50th stimuli were analyzed with FFT algorithm in the range of $0-100 \mathrm{~Hz}$ using 256 frequency bins. For the pre-stimulus period, the baseline spontaneous power during last $10 \mathrm{~s}$ before click train onset was analyzed in the range of $0-100 \mathrm{~Hz}$ using 256 frequency bins. For power spectral analysis during the post-stimulus period, LFP data obtained from a 10-s period (200-ms bin) $20 \mathrm{~min}$ after the cessation of all ASSR stimuli were analyzed with FFT algorithm in the range of $0-100 \mathrm{~Hz}$ using 256 frequency bins (see Figure 4A).

To calculate phase locking to auditory click- trains, phase locking was performed in a frequency range $0-100 \mathrm{~Hz}$ with a $60 \%$ overlapping window after applying Hanning tapering of normalized LFP data, which was further analyzed with FFT algorithm. To plot a scalogram (wavelet spectrogram), Matlab z-score files of LFP were wavelet transformed using a Complex Gaussian wavelet from Matlab wavelet toolbox.

\section{STATISTICS}

Given that between-animal variability may be larger than withinanimal variability in per-channel (i.e., per electrode) design, we mainly presented the data with per-animal design in the Figures and some data with per-channel design in the Supplemental Figures (see Lazic and Essioux, 2013). Differences between groups were assessed for normally distributed data using a Student's $t$ test (Statcel 2nd ed., OMS, Tokyo, Japan). The effect size was assessed as Cohen's $d$. For the graph data in Figures 4, 5, differences were assessed by repeated measures of ANOVAs followed by Bonferroni post-hoc analysis (SPSS, IBM). Data were presented as mean \pm s.e.m.

\section{RESULTS \\ ROBUST REDUCTION OF 40-Hz AUDITORY STEADY-STATE RESPONSES (ASSRs)}

Seven days after surgery, 40-Hz click train-evoked initial N1 responses (i.e., the transient auditory evoked potentials to click train onset, more than $0.1 \mathrm{mV}$ ) were detected in A1 cortex from 13 mice ( 7 fGluN1 control and 6 mutant mice), out of a total of 65 animals in which the click-train-evoked responses had been detected during the electrode implantation surgery. The relative high number of animals that displayed no evoked LFPs was mostly likely to be due to a shift of or damage to the electrode microarray placed on the temporal bone. Thirty-one LFP recordings from 7 control mice [animal \#1: 2 (number of recording sites to be analyzed)/6 (total channel number), \#2: 6/6, \#3: 3/6, \#4: 6/6, \#5: 6/6, \#6: 3/6, \#7: 5/6], and 26 LFP recordings from 6 mutant mice (animal \#1: 5/6, \#2: 4/6, \#3: 6/6, \#4: 5/6, \#5: 3/6, \#6: 3/6) were subjected to subsequent LFP in-depth analysis.

Fifty $40-\mathrm{Hz}$ click trains (duration, $500 \mathrm{~ms}$ ) were delivered to click train-naïve animals with an inter-stimulus interval of $20 \mathrm{~s}$. Figure 1A depicts representative examples of the averaged ASSRs (middle) and scalogram (wavelet spectrogram, bottom) evoked by $40 \mathrm{~Hz}$ stimulation (upper) in the floxed-control (left) and mutant mouse (right). Robust click train-evoked N1 potentials were elicited within the first $100 \mathrm{~ms}$ after click-train onset in both genotypes, and there were no differences in the averaged N1 amplitudes between genotypes per animal (Figure 1B). However, the N1 amplitudes averaged per channel were lower in the mutants compared to the floxed-control mice $(p<0.05$, Student's $t$-test, Supplemental Figure 1A). To assess the subsequent ASSRs coherent to the $40-\mathrm{Hz}$ click trains without any impact of evoked N1 potentials on the steady-state responses, LFP data (z-score) during last $200 \mathrm{~ms}$ before click-train cessation (a dashed line period in Figure 1A) were analyzed with an FFT algorithm. We found that the amplitudes of $40-\mathrm{Hz}$ ASSRs were smaller in the mutants compared to the controls per animal [Figure 1C, $t_{(11)}=2.8, p<0.05$, Cohen's $d=1.60$ (large effect size)] and per channel [Supplemental Figure 1B, $t_{(55)}=5.23, p<0.01, d=1.43$ (large effect size) $]$. Difference in evoked ASSR power from baseline spontaneous power during inter-stimulus intervals, which were obtained by subtracting the spontaneous power amplitudes in-between ASSR stimuli from total ASSR power (Figure 1E), also peaked at $40 \mathrm{~Hz}$ and, to the lessor degree, at $30 \mathrm{~Hz}$ in the controls. Conversely, only small differences were detected in the mutant mice (Figure 1D and Supplemental Figure 1C). Figure 1F and Supplemental Figure 1D showed power spectrum density difference from the baseline at $35-44 \mathrm{~Hz}$ for each animal $\left[n=7\right.$ controls, $n=6$ mutants, $t_{(11)}=$ 4.57, $p<0.01, d=2.64$ (large effect size)] and for each channel $[n=31$ sites from 7 controls, $n=26$ sites from 6 mutants, $t_{(55)}=7.79, p<0.01, d=2.14$ (large effect size)], indicating that average low gamma power for the evoked ASSRs was lower in the mutants compared to the controls. In addition, phase locking analysis of the $40-\mathrm{Hz}$ ASSRs (z-score) revealed two peaks at $40 \mathrm{~Hz}(35-44 \mathrm{~Hz})$ and at $80 \mathrm{~Hz}(75-84 \mathrm{~Hz})$ for both controls and mutants (Figure 1G), but only phase locking at $40 \mathrm{~Hz}$ in the mutants was lower in comparison to controls for each animal [Figure $1 \mathbf{H}, t_{(11)}=4.93, p<0.01, d=2.75$ (large effect size)] and for each channel [Supplement Figure 1E, $t_{(55)}=9.42, p<$ $0.01, d=2.47$ (large effect size)]. These findings suggest that mutants are severely impaired in $40-\mathrm{Hz}$ ASSR for both amplitude and phase locking, both of which are reminiscent of ASSR deficits in schizophrenia patients.

\section{DIMINISHED 20-Hz ASSR POWER AND PHASE-LOCKING}

We next examined $20-\mathrm{Hz}$ ASSRs (duration, $1000 \mathrm{~ms}$ ) to explore whether ASSR deficits are specific to $40-\mathrm{Hz}$ stimuli. Figure 2A 

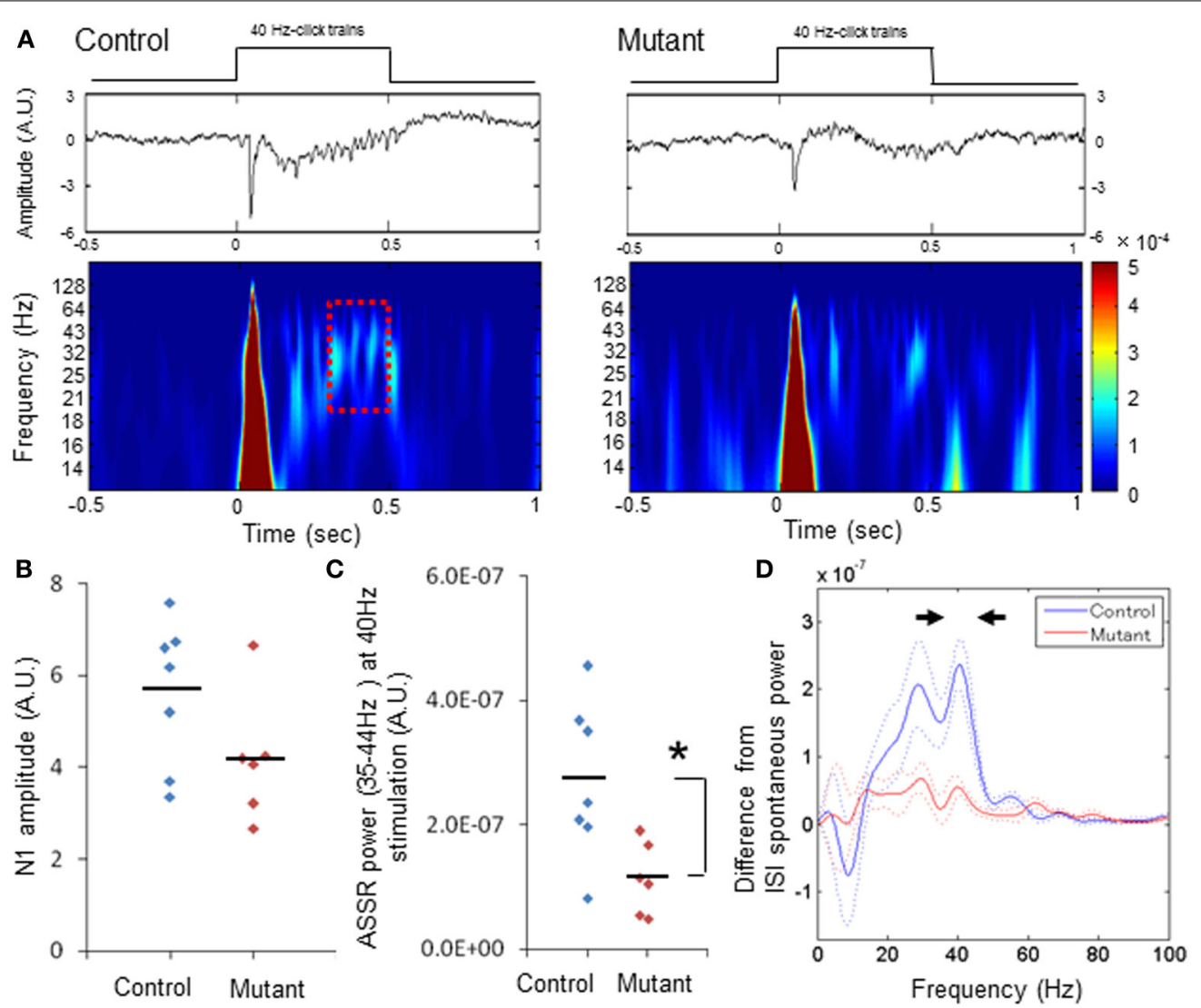

E

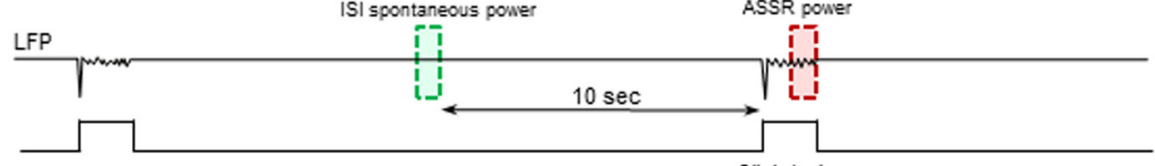

Click trains

F

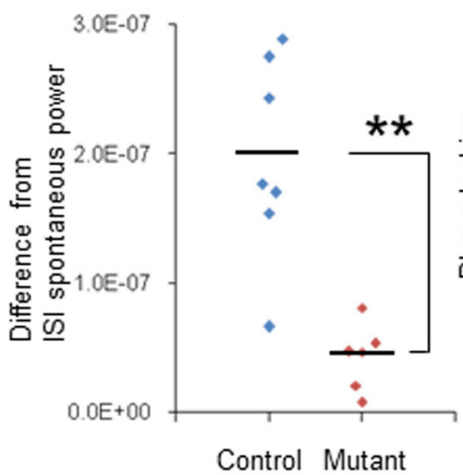

G

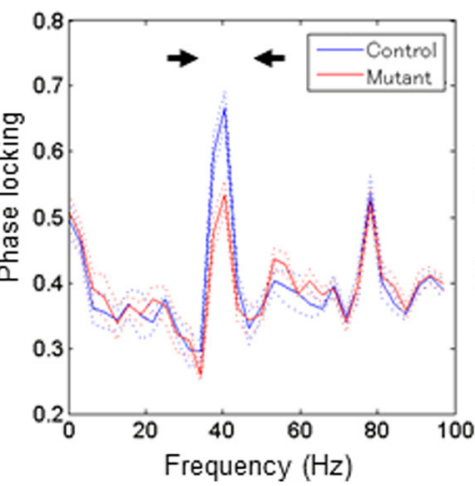

H

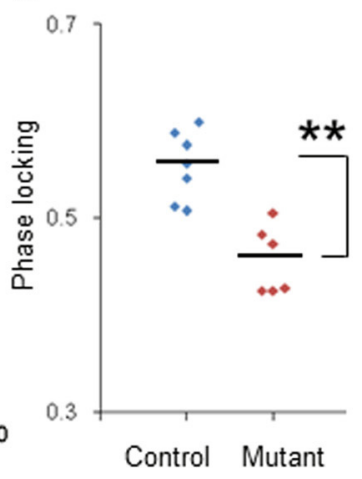

FIGURE 1 | Robust reduction in power and phase-locking of 40-Hz ASSRs. (A) Representative examples of the averaged 40-Hz ASSR (middle, z-score) and spectrogram (bottom) in response to $40-\mathrm{Hz}$ click trains (upper; $80 \mathrm{~dB}$ intensity, $500 \mathrm{~ms}$ duration). Time 0 is tone onset. (B) No difference in the averaged N1 amplitudes (z-score) evoked by $40-\mathrm{Hz}$ click trains between genotypes (blue for 7 fGluN1 control mice; red for 6 mutant mice). $p=0.11$, unpaired Student's t-test (C) Evoked ASSR power (z-score) at 35-44 Hz frequency range during $40-\mathrm{Hz}$ click train stimulation in mutants (red) was lower than controls (blue). $* p<0.05$, unpaired Student's $t$-test. (D) The mean difference (A.U.) from baseline spontaneous power during inter-stimulus interval (ISIs; green square in Panel E) in click train-evoked ASSR power during last $200 \mathrm{~ms}$ before cessation of $40-\mathrm{Hz}$ click trains (red square in Panels $\mathbf{A}, \mathbf{E}$ ). Dotted lines: mean \pm s.e.m. (E)
Schematic diagram indicates the analysis periods of baseline LFP power (green, ISI spontaneous power) and the evoked ASSR power (red). Relative ASSR power amplitudes shown in Panel (D) were calculated by subtracting an ISI power (in green) from the evoked ASSR power (in red) for each channel, and averaged per animal. (F) The difference in the magnitude between 35 and $44 \mathrm{~Hz}$ spectral power (arrowheads in Panel D) and the baseline for $40-\mathrm{Hz}$ ASSRs in mutants (red) was lower than controls (blue). ${ }^{* *} p<0.01$, unpaired Student's $t$-test. (G) Phase locking to $40-\mathrm{Hz}$ steady-state tone stimuli in control (blue) and mutant (red) mice. Dotted lines: mean \pm s.e.m. (H) Magnitude of 35-44 Hz phase locking for 40-Hz ASSRs (arrowheads in Panel G) in mutants (red) was lower than controls (blue). ${ }^{* *} p<0.01$, unpaired Student's $t$-test. Each dot represents individual animals. Dotted lines in Panels $(\mathbf{D}, \mathbf{G})$ are s.e.m. 

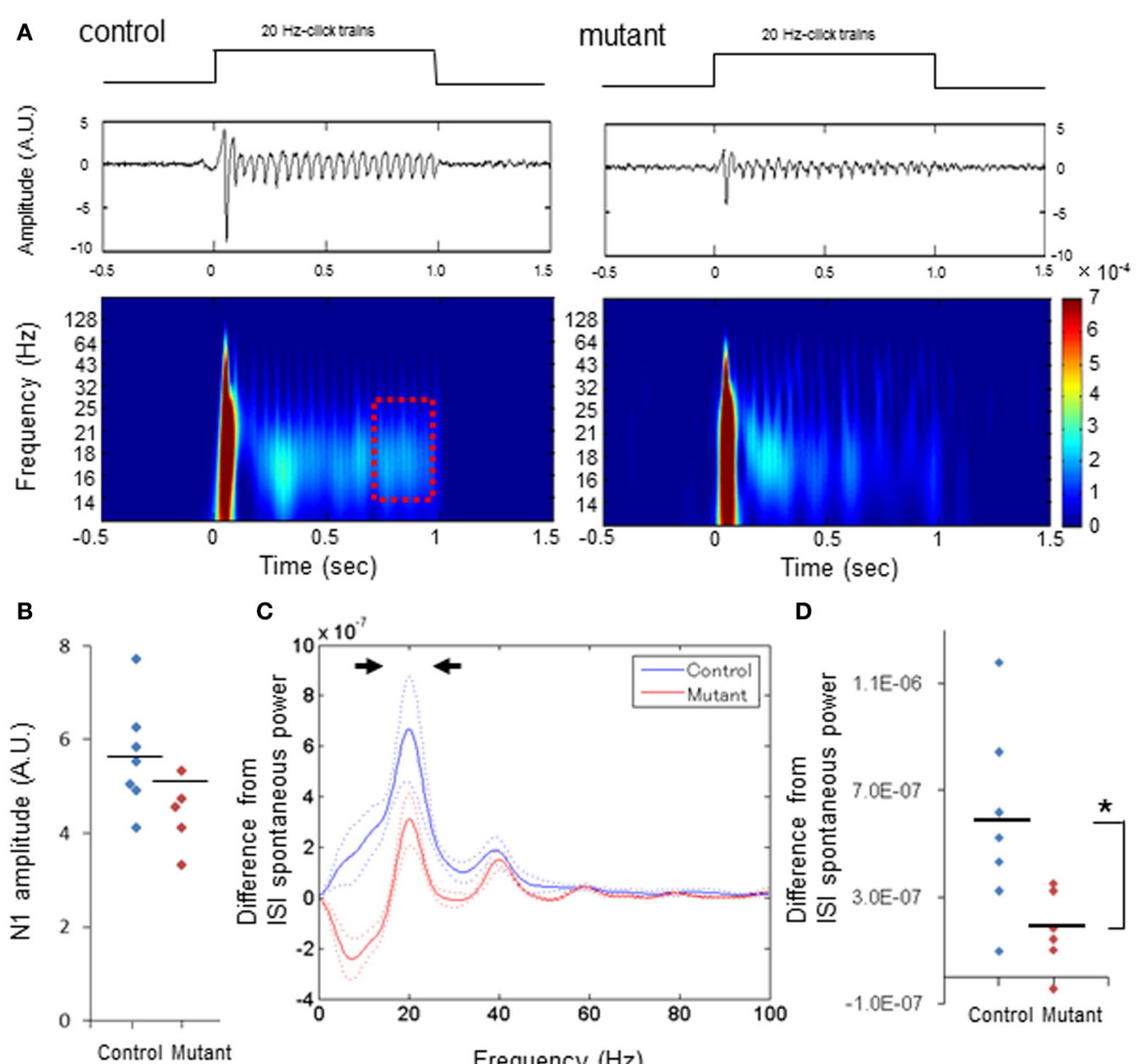

C
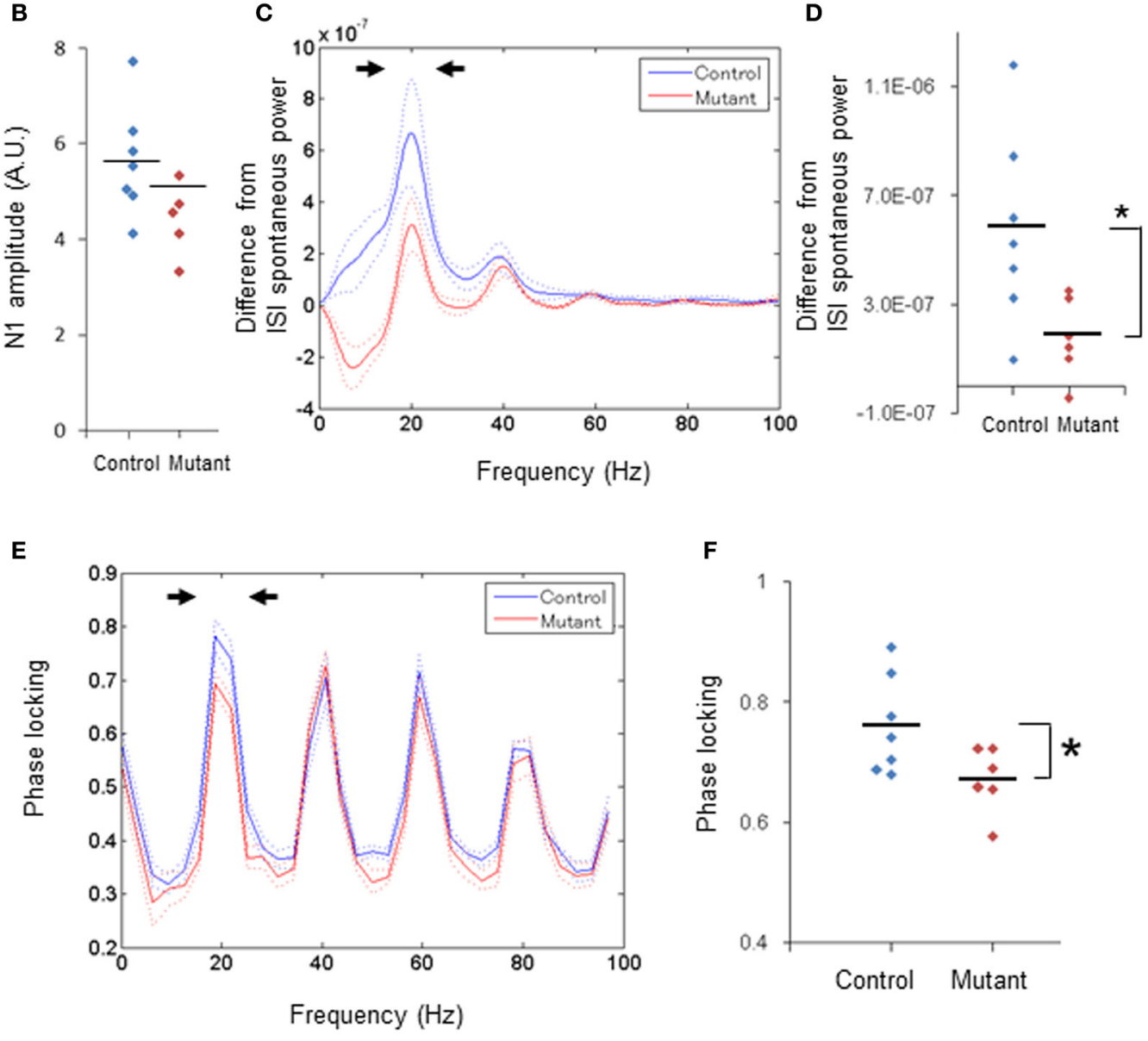

FIGURE 2 | Diminished power and phase-locking of 20-Hz ASSRs.

(A) Representative examples of the averaged $20-\mathrm{Hz}$ ASSR (middle, z-score) and spectrogram (bottom), in response to $20-\mathrm{Hz}$ click trains (upper; $80 \mathrm{~dB}$ intensity, $1000 \mathrm{~ms}$ duration). Time 0 is tone onset. (B) No difference in the averaged $\mathrm{N} 1$ amplitudes (z-score) evoked by $20-\mathrm{Hz}$ click trains between genotypes (blue for 7 fGluN1 control mice; red for 6 mutant mice). $p=0.54$, unpaired Student's $t$-test. (C) The mean difference (A.U.) from ISI spontaneous power in click train-evoked ASSR power during last $200 \mathrm{~ms}$ before cessation of $20 \mathrm{-Hz}$ click trains (red square in A) (blue for 7 fGluN1 controls; red for 6 mutants). Dotted lines: mean \pm s.e.m. (D) The difference in the magnitude between 15 and $24 \mathrm{~Hz}$ power (arrowheads in C) from ISI spontaneous power for $20-\mathrm{Hz}$ ASSRs was lower in mutant mice (red). ${ }^{*} p<0.05$, unpaired Student's t-test. (E) Phase locking to $20-\mathrm{Hz}$ ASSR stimuli in control (blue) and mutant (red) mice. Dotted lines: mean \pm s.e.m. (F) Magnitude of $15-24 \mathrm{~Hz}$ phase locking for $20-\mathrm{Hz}$ ASSRs (arrowheads in E) was lower in mutant mice (red). ${ }^{*} p<0.05$ unpaired Student's $t$-test. Each dot represents individual animals. Dotted lines in (C,E) are s.e.m. 
depicts a representative example of the averaged evoked potentials (middle) and spectrogram (bottom) evoked by $20-\mathrm{Hz}$ click trains (upper) in control (left) and mutant mice (right). First, we found no difference in the averaged N1 amplitudes between genotypes analyzed per animal (Figure $2 B$ ) or analyzed per channel (Supplemental Figure 2A). The difference in the evoked ASSR power, which were obtained by subtracting the spontaneous power amplitudes in between ASSR stimuli from the total ASSR power during last $200 \mathrm{~ms}$ before cessation of click-trains (dashed period in Figure 2A), also peaked at $20 \mathrm{~Hz}$ with a smaller peak at the $40 \mathrm{~Hz}$ harmonic in both genotypes (Figure 2C and Supplemental Figure 2B). However, the relative power of the dominant peak at $20 \mathrm{~Hz}(15-24 \mathrm{~Hz})$ was lower in the mutants compared to controls per animal [Figure 2D, $t_{(11)}=2.59, p<$ $0.05, d=1.47$ (large effect size)] and in per-channel design [Supplemental Figure $2 \mathrm{C}, t_{(55)}=4.58, p<0.01, d=1.25$ (large effect size)]. Furthermore, phase locking of the 20-Hz ASSR consisted of a dominant peak at $20 \mathrm{~Hz}$ with several spectral peaks at harmonics of $20 \mathrm{~Hz}$ (Figure 2E and Supplemental Figure 2D). The dominant peak of phase locking factor at $15-24 \mathrm{~Hz}$ in the mutants was lower than the controls analyzed per animal [Figure 2F, $t_{(11)}=2.29, p<0.05, d=1.3$ (large effect size)] and analyzed per channel [Supplemental Figure $2 \mathrm{E}, t_{(55)}=3.77$, $p<0.01, d=1.01$ (large effect size)], but other spectral peaks in the mutants were similar to those in controls per animal $(p=$ 0.63 for $35-44 \mathrm{~Hz}, p=0.37$ for $55-64 \mathrm{~Hz}, p=0.40$ for $75-84 \mathrm{~Hz}$, unpaired Student's $t$-test) and per channel ( $p=0.44$ for $35-$ $44 \mathrm{~Hz}, p=0.27$ for $55-64 \mathrm{~Hz}, p=0.50$ for $75-84 \mathrm{~Hz}$, unpaired Student's $t$-test). These results indicate both ASSR and phaselocking evoked by $20-\mathrm{Hz}$ ASSR stimuli are also diminished in the mutant mice, while the magnitudes of auditory-evoked potentials triggered by $20-\mathrm{Hz}$ stimuli are largely unaffected.

\section{ENHANCED SPONTANEOUS LFP POWER IN AWAKE QUIESCENT PERIOD}

To systematically explore the levels of spontaneous power throughout the periods of inter-ASSR stimulus intervals and the post-ASSR period, we further assessed the transition of spontaneous LFP power ( $\mathrm{z}$-score) from the pre-stimulus period to the inter-stimulus periods post to the first, 25th and 50th $40-\mathrm{Hz}$ clicktrain administration, and the post-stimulus period $20 \mathrm{~min}$ after the cessation of last (50th) $40-\mathrm{Hz}$ click-train (Figure 3A). First, we assessed the power spectra of $z$-score normalized LFPs during the pre-stimulus period from awake head-restrained animals. We found that baseline spontaneous power during the last 10-s prestimulus period prior to the first click-train administration was augmented in the mutants compared to the controls regardless of the spectral frequency found in both per-animal (Figure 3B) and per-channel (Supplemental Figure 3A) design. The intensities of averaged power for baseline LFPs at low gamma $(30-50 \mathrm{~Hz})$ and high gamma $(50-100 \mathrm{~Hz})$ range were both higher in the mutant mice compared to the controls per animal [Figure 3C, $t_{(11)}=$ 3.00, $p<0.01, d=1.67$ for low gamma; $t_{(11)}=3.13, p<0.01$, $d=1.74$ for high gamma] and per channel [Supplemental Figure $3 \mathrm{~B}, t_{(55)}=6.41, p<0.01, d=1.66$ for low gamma; $t_{(55)}=5.56$, $p<0.01, d=1.46$ for high gamma]. This elevation of LFP fluctuation continued even at super gamma frequency $(100-120 \mathrm{~Hz})$ per animal $\left[t_{(11)}=2.41, p<0.05, d=1.33\right.$ (large effect size)] and per channel $\left[t_{(55)}=4.68, p<0.01, d=1.24\right.$ (large effect size)], suggesting a broadband LFP power increase in the mutant animals during the awake quiescent period.

\section{SPONTANEOUS LFP POWER RETURNS BACK TO NORMAL UPON ASSR STIMULI}

After the $40-\mathrm{Hz}$ ASSR session began, we found a clear trend of a gradual reduction in mutant spontaneous LFP power amplitudes during inter-stimulus intervals with the increasing number of ASSR stimuli (Figures 4A-C, 5A-C). For example, spontaneous LFP power per animal was reduced in the inter-stimulus period following the 25th ASSRs, compared to the pre-ASSR period at $35-44 \mathrm{~Hz}$ [Figure $4 \mathrm{~B}, F_{(1,11)}=1.389, p=0.263$ for genotype, Bonferroni post-hoc test, $p<0.05]$. In per-channel design, spontaneous LFP power at $21-30 \mathrm{~Hz}$ [Figure 5A, $F_{(1,54)}=1.326$, $p=0.255$ for genotype, Bonferroni post-hoc test, $p<0.05]$, 35-44 Hz [Figure 5B, $F_{(1,54)}=6.392, p=0.014$ for genotype, Bonferroni post-hoc test, $p<0.05$ ], and $71-80 \mathrm{~Hz}$ [Figure 5C, $F_{(1,54)}=2.707, p=0.106$ for genotype, Bonferroni post-hoc test, $p<0.05$ ], were all decreased by the 25 th ISI in the mutants. On the other hand, the spontaneous LFP power in the control mice tended to increase after the 1st ASSR stimuli, particularly in beta frequency range (Figure 4A). This power increase upon ASSR stimuli in the control mice was prominent in the per-channel design (Figures 5A,B, $p<0.05$, respectively). Consequently, no genotypic difference was detected in spontaneous LFP power magnitudes during 10-s inter-stimulus intervals (combined data of first, 25th and 50th ISIs) at any power spectra examined per animal (Figure 4D) and per channel (Figure 5D). Interestingly, 20-min after the last ASSR, the spontaneous LFP power in the mutants was significantly augmented [Figure $4 \mathrm{~A}, F_{(1,11)}=$ 1.104, $p=0.335$ for genotype, Bonferroni post-hoc test, $p<$ 0.05] to the level of pre-stimulus period. The elevation of LFP power amplitudes was more prominent in per channel analysis (Figures 5A-C, $p<0.05$ ). These results suggest a brain statedependent abnormality of baseline spontaneous LFP power in the mutant mice, i.e., an abnormally high spontaneous LFP power in an awake quiescent period, which disappears upon receiving external auditory stimuli. Our findings also strongly suggests that the evoked ASSR deficit found in our mutants is not due to greater baseline spontaneous gamma power, rather it is simply caused by the deficits in evoking responses by external stimuli.

\section{DISCUSSION}

We demonstrated abnormal oscillatory LFP power and impaired auditory-evoked LFP responses from the auditory cortex of awake, head-restrained GABA neuron-specific NMDAR hypofunction mice. Specifically, we found (1) a profound reduction of ASSR power and phase locking at $40-\mathrm{Hz}$, and to lesser degree, at $20-\mathrm{Hz}$, and (2) a broadband increase in spontaneous LFP power during the pre-stimulus period, but not during the inter-ASSR stimulus intervals. Interestingly, abnormal elevation of baseline spontaneous LFP power during the prestimulus period disappeared after the ASSR stimuli were presented. These finding suggest that NMDAR hypofunction in cortical GABAergic interneurons leads to two temporally distinct, brain state-dependent LFP deficits in A1 cortex; (1) the evoked ASSR deficits with normal level of spontaneous LFP 


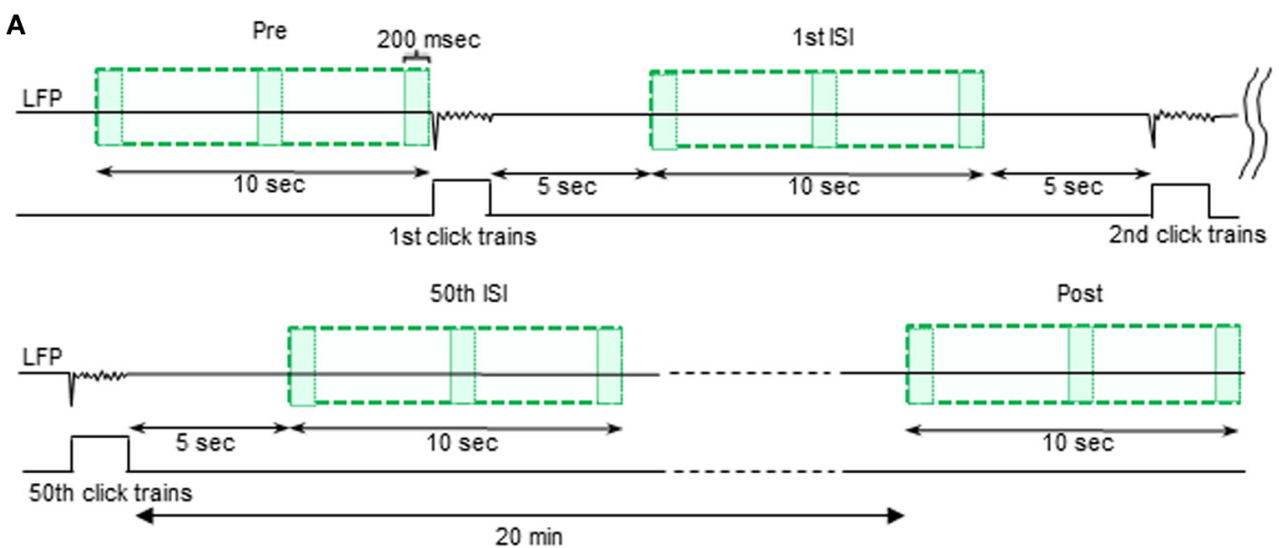

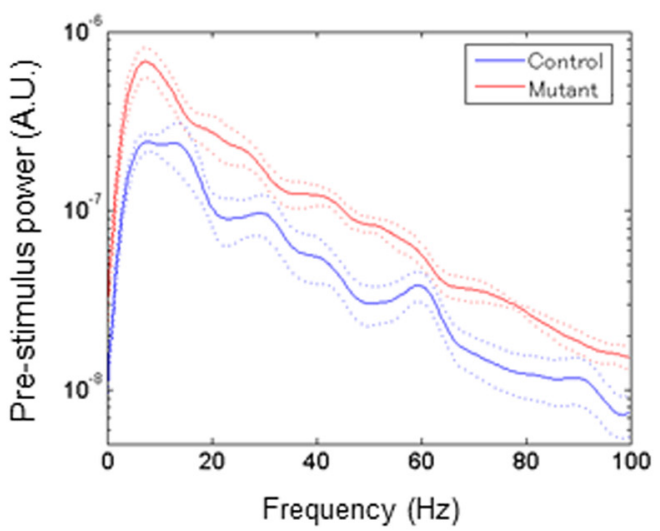

C

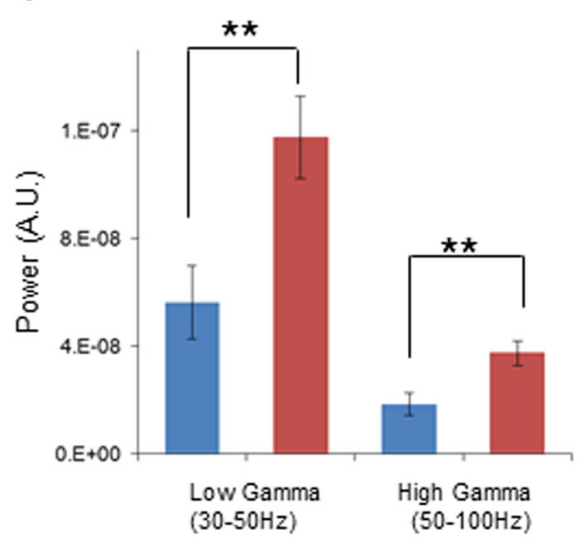

FIGURE 3 | Broadband elevation of mutant spontaneous LFP power during pre-stimulus period. (A) Schematic diagram indicates the analysis periods of spontaneous LFP power during pre-stimulus period (Pre), following the first ASSR stimuli [1st inter-stimulus interval (ISI)], following the 50th ASSR stimuli (50th ISI), and during post-stimulus period (Post). For a pre-stimulus period, z-score normalized LFPs (top line) during last $10 \mathrm{~s}$ (upper left green square) before the first click train onset were analyzed with FFT algorism with every 200-ms bin (each box). During ASSR sessions, LFP data from 5 to $15 \mathrm{~s}$ (200-ms bin) after the 1 st stimuli (upper right green square), the 25th stimuli (not shown), and 50th stimuli (bottom left green square) were analyzed with FFT algorithm. For a post-stimulus period, LFPs were obtained from a 10-s period (bottom right green square) 20 min after cessation of the last click trains were analyzed with FFT algorithm (200-ms bin). (B) Z-score normalized spectral density power during pre-stimulus period from control (blue) and mutant (red) mice (control: $n=7$, mutant: $n=6$ ). Dotted lines: mean \pm s.e.m. A 60-Hz bump in control LFP power spectra was due to power line noise contamination. (C) Averaged spontaneous LFP powers at low gamma $(30-50 \mathrm{~Hz})$, high gamma $(50-100 \mathrm{~Hz})$ frequency range were higher in mutant (red) mice compared to control mice (blue). ${ }^{* *} p<0.01$, unpaired Student's t-test. power and (2) abnormal broadband elevation of spontaneous LFP power when no auditory stimuli are presented. Our study also showed no obvious contribution to the evoked ASSR deficits of augmented spontaneous LFP fluctuation following NMDAR hypofunction in GABAergic interneurons.

\section{POTENTIAL MECHANISMS UNDERLYING EVOKED ASSR DEFICITS}

We demonstrated robust ASSR deficits in the mutant mice in which NMDARs were selectively eliminated from 75 to $84 \%$ of PV-containing interneurons in neocortex (Belforte et al., 2010). This suggests that NMDARs in the PV-positive fast-spiking neurons are crucial for emergence of ASSRs. Optogenetically evokedgamma oscillations have also been shown to be defective in mice in which NMDARs are genetically ablated from all PV-positive neurons (Carlén et al., 2012). The mechanism by which NMDAR deletion from PV neurons results in the ASSR deficits in not fully known. However, activation of cortical PV-positive interneurons in the thalamorecipient circuit is known to enhance acoustic information flow by feed-forward inhibition, which contributes to improved signal-to-noise ratio (Hamilton et al., 2013). In particular, the firing rate of fast-spiking neurons, likely PV-positive, appears to increase with increasing attention to external stimuli (Mitchell et al., 2007; Chen et al., 2008). It is noted that although selective genetic GluN1 deletion also occurs in $\sim 30 \%$ of Reelinpositive interneurons in the mutant cortex, Reelin-positive neurons are located mostly in the supra-granular layers. Therefore, the most likely mechanism for our observation is a functional deficit in the NMDAR-deleted PV neurons that receive thalamocortical afferents. Presumed impairment in their feed-forward inhibition in response to acoustic stimuli may attenuate the generation of auditory evoked potentials followed by gamma oscillations. Further research exploring whether NMDAR hypofunction in cortical PV-neurons disturbs feedforward information flow elicited by auditory stimuli in Al cortex is warranted. 

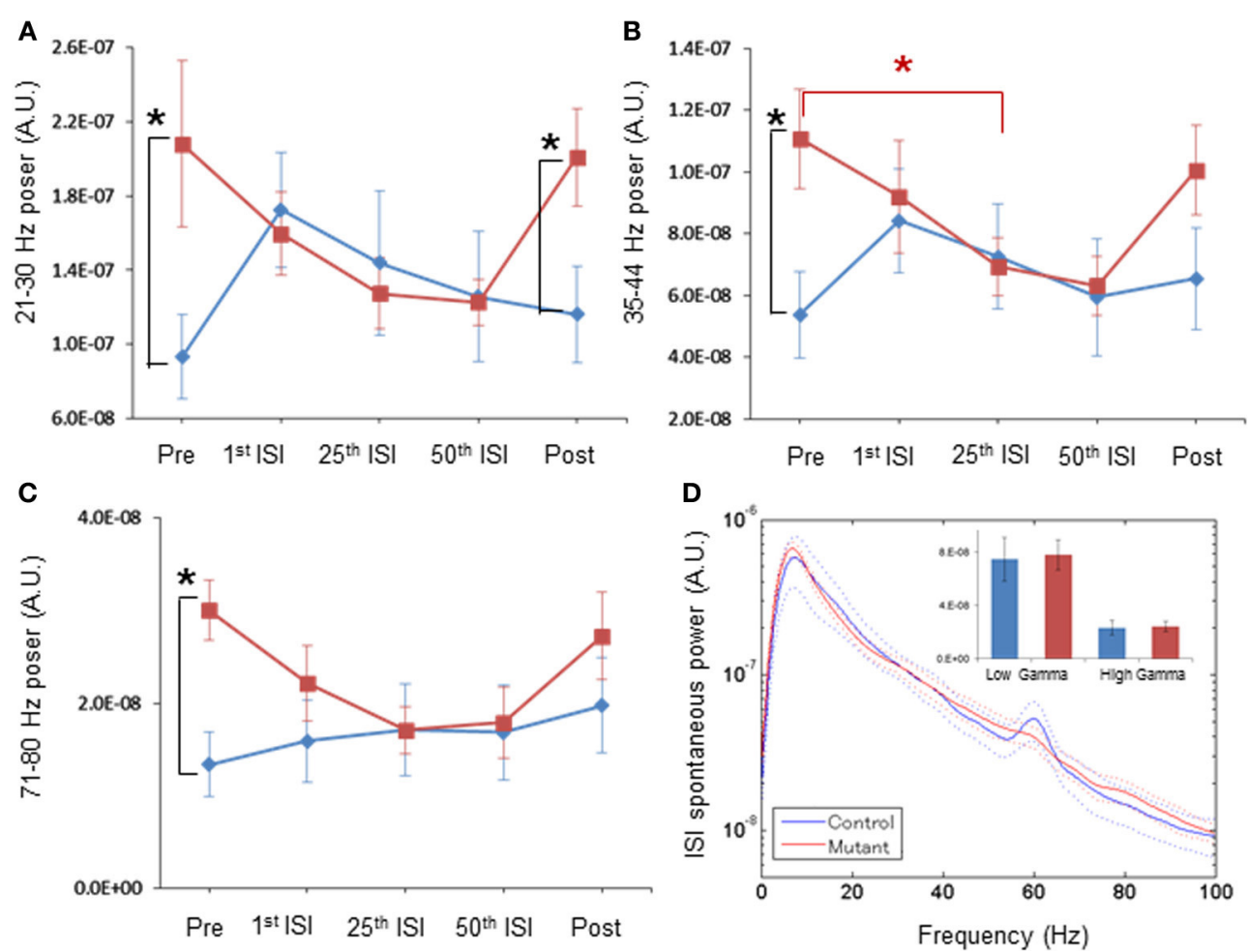

FIGURE 4 | Normal magnitude of baseline LFP power during periods of periodic ASSR stimuli, by per-animal design. (A) Transition of $z$-score normalized spontaneous LFP powers per animal at $21-30 \mathrm{~Hz}$ frequency in control (blue) and mutant (red) mice during Pre (pre-stimulus period), 1st ISI (first inter-stimulus interval), 25th ISI, 50th ISI, and Post (post-stimulus period). ${ }^{*} p<0.05$. (B) Transition of spontaneous LFP powers at $35-44 \mathrm{~Hz}$ in control (blue) and mutant (red) mice. ${ }^{*} p<0.05$. (C) Transition of spontaneous LFP powers at $71-80 \mathrm{~Hz}$ in control (blue) and mutant (red) mice. ${ }^{*} p<0.05$. Repeated-measures ANOVA followed by post-hoc Bonferroni testing. (D) No differences in averaged spontaneous LFP power amplitudes in the first, the 25th and the 50th ISIs, across frequencies between control (blue, $n=7$ ) and mutant (red, $n=6)$ mice. The inset shows no difference in average LFP power amplitudes at low gamma $(30-50 \mathrm{~Hz})$ and high gamma $(50-100 \mathrm{~Hz})$ frequency. A $60-\mathrm{Hz}$ bump in control LFP power spectra was due to power line noise contamination. Dotted lines: mean \pm s.e.m.

\section{POTENTIAL MECHANISMS UNDERLYING THE ENHANCED BASELINE LFP FLUCTUATION}

We also observed elevated spontaneous LFP oscillatory power in the pre-stimulus period before the animal attends to the auditory stimuli. Since genetic ablation of NMDARs selectively from PV neurons in awake mice also results in increased baseline power (Korotkova et al., 2010; Carlén et al., 2012), this finding is most likely due to NMDAR hypofunction in PV neurons. Similar results were also obtained from GluN1 hypomorph mice (Dzirasa et al., 2009; Gandal et al., 2012b) and from the acute administration of NMDAR antagonists (phencyclidine, ketamine, or MK801) to rodents (Leung, 1985; Ma and Leung, 2000, 2007; Pinault, 2008; Ehrlichman et al., 2009; Hakami et al., 2009; Páleníček et al., 2011; Kulikova et al., 2012; Wood et al., 2012; Caixeta et al., 2013; Molina et al., 2014), to humans (Maksimow et al., 2006; Hong et al., 2010), and in in vitro slice preparation (McNally et al., 2011). The most likely mechanistic explanation for these effects is that cortical disinhibition elicited by NMDAR deletion from local PV neurons render the cortical glutamatergic neurons hyperexcitable (Olney and Farber, 1995; Homayoun and Moghaddam, 2007; Lisman et al., 2008; Nakazawa et al., 2012). However, the NMDAR hypofunction-induced baseline power increase is unlikely to be caused by hyper-synchrony of spiking activity. A recent in vivo unit/LFP recording study revealed that cortical disinhibition elicited by MK-801, a NMDAR antagonist, evoked an increase in the number of random spike trains of individual units and consequently a reduced synchronized firing of action potentials in $\mathrm{mPFC}$ of free-moving rats, despite a robust increase in LFP power at gamma frequency (Molina et al., 2014). This finding suggests a decoupling of gamma band LFP power from neuronal spiking synchrony. Similarly, we also previously reported in the same mutant mice used in this study there was a disruption in in vivo spike synchrony among pyramidal neurons in somatosensory cortex (Belforte et al., 2010). Therefore, the spontaneous LFP power increase following cortical NMDAR hypofunction may simply reflect a robust increase in synaptic inputs with aberrant or "noisy" spike firing. It is also plausible that NMDAR antagonism on GABAergic neurons in the basal ganglia and/or thalamic reticular nucleus causes disinhibition of thalamocortical neurons, leading to massive stimulation of cortical neurons at gamma frequency (Llinás and Ribary, 1993; Santana et al., 2011). However, this is unlikely in our model because the genetic manipulation is largely confined to the cortex and hippocampus. 


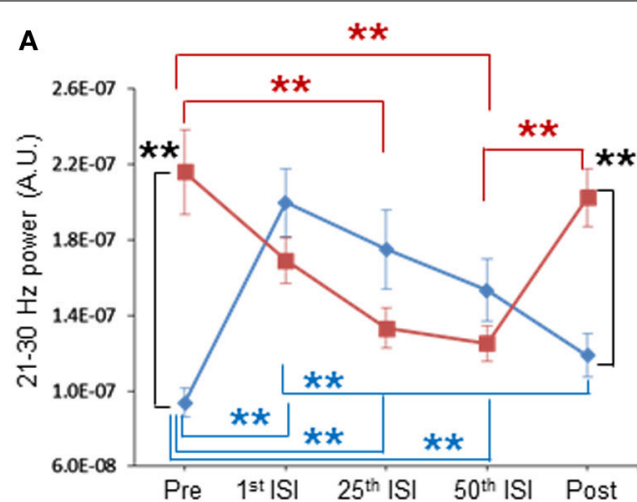

C

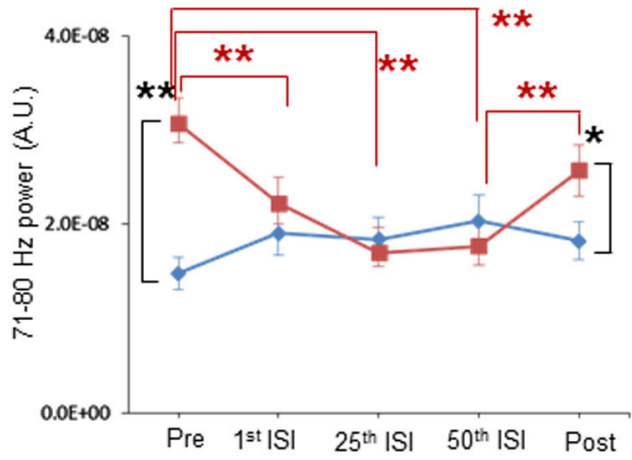

FIGURE 5 | Normal magnitude of baseline LFP power during periods of periodic ASSR stimuli, by per-channel design. (A) Mean normalized powers in per channel design for $21-30 \mathrm{~Hz}$ frequency LFP fluctuation in control (blue, $n=31$ sites from 7 animals) and mutant (red, $n=26$ sites from 6 animals) mice during Pre-ASSR, 1st ISI, 25th ISI, 50th ISI, and post-ASSR. ${ }^{* *} p<0.01$, repeated-measures ANOVA followed by post-hoc Bonferroni testing. (B) Mean normalized powers for $35-44 \mathrm{~Hz}$ frequency LFP fluctuation in control (blue) and mutant (red) mice during Pre-ASSR, 1st ISI, 25th ISI, 50th ISI, and Post-ASSR. ${ }^{* *} p<0.01$ and ${ }^{*} p<0.05$, repeated-measures ANOVA followed by post-hoc Bonferroni testing. (C) Mean normalized

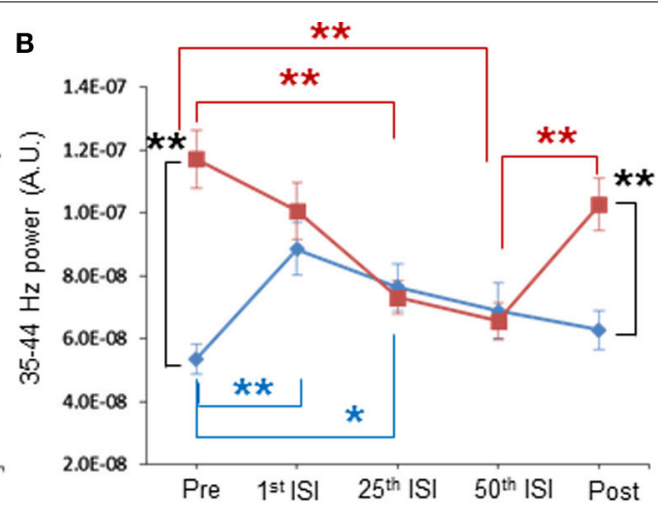

D

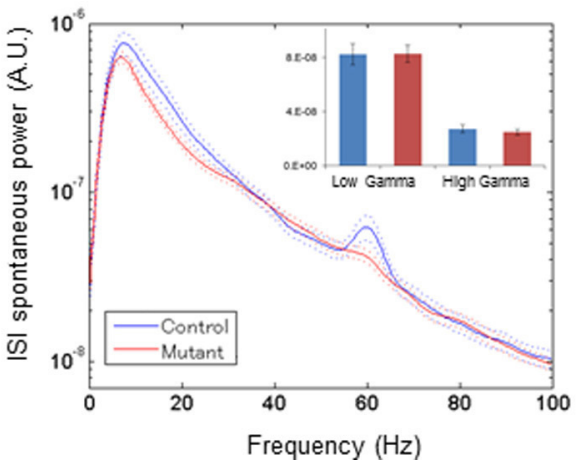

powers for $71-80 \mathrm{~Hz}$ frequency LFP fluctuation in control (blue) and mutant (red) mice during Pre-ASSR, 1st ISI, 25th ISI, 50th ISI, and Post-ASSR. ${ }^{* *} p<0.01,{ }^{*} p<0.05$, repeated-measures ANOVA followed by post-hoc Bonferroni testing. (D) No differences in averaged spontaneous LFP power amplitudes in the first, the 25th and the 50th ISIs, across frequencies between control mice (blue, $n=31$ sites from 7 animals) and mutant mice (red, $n=26$ sites from 6 animals). The inset shows no difference in average LFP power amplitudes at low gamma $(30-50 \mathrm{~Hz})$ and high gamma $(50-100 \mathrm{~Hz})$ frequency. A $60-\mathrm{Hz}$ bump in control LFP power spectra was due to power line noise contamination. Dotted lines: mean \pm s.e.m.
BRAIN STATE-DEPENDENT ELEVATION OF SPONTANEOUS LFP POWER Unexpectedly, we found that spontaneous LFP power amplitudes tends to decrease during the repeated ASSR stimuli; a phenomenon which was more robust in per-channel design (Figure 5). Accordingly, the broadband elevation of spontaneous LFP power in the pre-stimulus period (Figure 3B) disappeared during the inter-ASSR stimulus periods (Figure 4D). The structure of cortical spontaneous activity is known to vary with cortical state or behavioral state (Steriade et al., 2001; Harris and Thiele, 2011). During the slow-wave sleep period and awake quiescent period, auditory cortex exhibits fluctuations of global activity between "synchronized" states of larger low frequency waves known as up and down state (Steriade et al., 1993; Harris and Thiele, 2011). In active wakefulness during tone presentation, these fluctuations are replaced by the "desynchronized" state characterized by low amplitude, high frequency LFPs (Castro-Alamancos, 2004). It has been reported that superficial pyramidal cells and putative fast-spiking neurons in rat A1 cortex dominate in awake quiescent period, and their activity was largely suppressed during auditory stimuli-induced cortical desynchronization (Sakata and Harris, 2012). The firing of fastspiking neurons in rat somatosensory cortex, which is highly active during quiet wakefulness, is also dramatically suppressed during active whisking behavior (Gentet et al., 2010). Considering that the majority of cell-types in which NMDAR elimination occurred in our mutant mice are PV-positive fast-spiking neurons, it is conceivable that the state-dependent elevation of spontaneous LFP power reflects the dysfunction of mutant A1 cortex fast-spiking neurons during awake quiescent period. However, a recent study showed a dramatic increase in the putative fastspiking neurons in visual cortex by the active running in a head-restrained condition that may elicit desynchronized state (Niell and Stryker, 2010). Further study is necessary to clarify the mechanisms of the state-dependent elevation of spontaneous LFP power observed in our mutant mice.

\section{COMPARISON TO CLINICAL DATA}

Overall, the present results were consistent with the clinical EEG data showing reductions in the onset of auditory evoked responses $(\mathrm{P} 50, \mathrm{~N} 100)$ and of $40-\mathrm{Hz}$ ASSR power and 
phase-locking in the cortex of individuals with schizophrenia, supporting the face validity of our mouse model. Furthermore, our findings argue against the possibility that $40-\mathrm{Hz}$ ASSR deficits in patients with schizophrenia may reflect antipsychotic effects (Woo et al., 2010). However, we also found several findings inconsistent with the human data. First, in human adult subjects $40-\mathrm{Hz}$ click trains induce the maximal ASSR at $40 \mathrm{~Hz}$ and the effects of $40-\mathrm{Hz}$ stimuli at 20 and $30 \mathrm{~Hz}$ are smaller compared to $40 \mathrm{~Hz}$ (Galambos et al., 1981; Pastor et al., 2002; Picton et al., 2003). Since the optimal input frequency of fast-spiking neurons for action potential generation is known to be $30-50 \mathrm{~Hz}$ in rats (Pike et al., 2000), the ASSR impairment selectively at $40 \mathrm{~Hz}$ stimulation may suggest unequivocal deficits of fast-spiking neurons in patients with schizophrenia. In our study, however, $40-\mathrm{Hz}$ stimuli induced a resonance peak at $30 \mathrm{~Hz}$ in addition to the $40-\mathrm{Hz}$ peak (Figure 1D) whereas the phase locking spectrum showed a peak only at $40 \mathrm{~Hz}$ (Figure 1G). This may suggest that the murine A1 cortex exhibits a broader resonance frequency $(30 \mathrm{~Hz}$ as well as $40 \mathrm{~Hz}$ ) than in humans; although no power peak at $30 \mathrm{~Hz}$ was detected when stimulated at $20 \mathrm{~Hz}$ (Figure 2B). Further study is warranted to determine whether the resonant frequency to auditory stimuli is varied depending on the species.

Second, 20-Hz ASSRs are usually unaffected in schizophrenia (Kwon et al., 1999; Light et al., 2006; Vierling-Claassen et al., 2008); however some human ASSR studies also showed attenuation in 20-Hz ASSRs (Krishnan et al., 2009). In contrast, in our model $20 \mathrm{~Hz}$ ASSRs are reduced in power and phase locking (Figure 2). Nonetheless, the mutant ASSR peak at $20 \mathrm{~Hz}$ was still visible (Figure 2B) and attenuation of phase locking at $20 \mathrm{~Hz}$ was modest (Figure 2E), compared to robustness of $40-\mathrm{Hz}$ ASSR deficits. Furthermore, the initial N1 responses triggered by 20 $\mathrm{Hz}$ ASSR stimuli were normal in the mutant mice. Therefore, the degree of evoked ASSR deficits appears to be more robust at 40$\mathrm{Hz}$ than at $20-\mathrm{Hz}$ in our mutant mice. It is conceivable that LFP recording directly from A1 cortex is more sensitive to detect ASSR impairment, compared to clinical skull-EEG recording.

Third, broadband enhancement of baseline EEG may not be characteristic of studies of resting EEG in patients with schizophrenia (Winterer et al., 2004; Kikuchi et al., 2011; Silverstein et al., 2012). However, Spencer (2012) re-analyzed their previous data which showed deficits in auditory evoked gamma oscillations and found that the pre-stimulus baseline gamma power was increased in the left auditory cortex of chronic patients. Interestingly, in his study, the baseline power increased across a wide frequency band $(15-100 \mathrm{~Hz})$ and this broadband increase was marginally significant, which is consistent with our finding.

Finally, this study involved relatively small sample sizes under per-animal analysis design (7 control and 6 mutant mice), which could be a confounding factor. However, nearly the same results were obtained by per-channel analysis (for example, Figure 4 vs. Figure 5), which further supports our conclusion.

\section{CLINICAL MANIFESTATION OF BASELINE LFP POWER INCREASE}

Given that sensory-evoked gamma oscillation deficits are presumably linked to the cognitive deficits (Spencer et al., 2004; Cho et al., 2006), there are several possible clinical manifestation of baseline power increase. Increased baseline gamma oscillations have been reported in patients during psychotic episodes, including visual and auditory hallucinations (Baldeweg et al., 1998; Ropohl et al., 2004; Lee et al., 2006; Becker et al., 2009). Other studies suggest a link between baseline gamma oscillations and negative symptoms (Suazo et al., 2012), working memory (Winterer et al., 2004; Suazo et al., 2012), or synaptic plasticity (Bikbaev et al., 2008; Kulikova et al., 2012). A recent metaanalysis of functional neuroimaging in schizophrenia patients with auditory hallucinations revealed "paradoxical" engagement of A1 cortex, such that left A1 cortex displayed increased activation in the absence of external auditory stimuli (but with auditory verbal hallucinations), and decreased activation when an external stimulus was actually present (Kompus et al., 2011). Consistent with this, our mutant mice also exhibited an increase in baseline spontaneous LFP increase in the absence of external stimuli, which tended to decrease during repetitive ASSR stimuli and to return back to the elevated level $20 \mathrm{~min}$ after the last ASSR stimuli. This remarkable similarity between human patient studies and the finding in the present study may suggest that baseline LFP power increase is a signature of "paradoxical" A1 cortex activation in the absence of external stimuli. Further studies are warranted to assess the clinical and neurobiological significance of oscillations and synchrony deficits in schizophrenia.

\section{AUTHOR CONTRIBUTIONS}

Kazuhito Nakao conceived and designed the study, performed the experiments, assembled, analyzed and interpreted the data, and wrote manuscript. Kazu Nakazawa conceived and designed the study, interpreted the data, and wrote the manuscript.

\section{ACKNOWLEDGMENTS}

This work was supported by an NIH grant K22MH099164 (Kazu Nakazawa) and by NIH Intramural Research Program. We thank Stefan Kolata and Kentaroh Takagaki for their advice on the earlier version of manuscript.

\section{SUPPLEMENTARY MATERIAL}

The Supplementary Material for this article can be found online at: http://www.frontiersin.org/journal/10.3389/fnins.2014. 00168/abstract

\section{REFERENCES}

Baldeweg, T., Spence, S., and Hirsch, S. R. (1998). Gamma-band electroencephalographic oscillations in a patient with somatic hallucinations. Lancet 352, 620-621. doi: 10.1016/S0140-6736(05)79575-1

Becker, C., Gramann, K., Müller, H. J., and Elliott, M. A. (2009). Electrophysiological correlates of flicker-induced color hallucinations. Conscious. Cogn. 18, 266-276. doi: 10.1016/j.concog.2008.05.001

Belforte, J. E., Zsiros, V., Sklar, E. R., Jiang, Z., Yu, G., Li, Y., et al. (2010). Postnatal NMDA receptor ablation in corticolimbic interneurons confers schizophrenia-like phenotypes. Nat. Neurosci. 13, 76-83. doi: 10.1038/ nn.2447

Bikbaev, A., Manahan-vaughan, D., and Sandi, C. (2008). Relationship of hippocampal theta and gamma oscillations to potentiation of synaptic transmission. Front. Neurosci. 2:1. doi: 10.3389/neuro.01.010.2008

Brenner, C. A., Krishnan, G. P., Vohs, J. L., Ahn, W.-Y., Hetrick, W. P., Morzorati, S. L., et al. (2009). Steady state responses: electrophysiological assessment of sensory function in schizophrenia. Schizophr. Bull. 35, 1065-1077. doi: 10.1093/schbul/sbp091 
Brenner, C. A., Sporns, O., Lysaker, P. H., and O'Donnell, B. F. (2003). EEG synchronization to modulated auditory tones in schizophrenia, schizoaffective disorder, and schizotypal personality disorder. Am. J. Psychiatry 160, 2238-2240. doi: 10.1176/appi.ajp.160.12.2238

Caixeta, F. V., Cornélio, A. M., Scheffer-Teixeira, R., Ribeiro, S., and Tort, A. B. L. (2013). Ketamine alters oscillatory coupling in the hippocampus. Sci. Rep. 3:2348. doi: 10.1038/srep02348

Carlén, M., Meletis, K., Siegle, J. H., Cardin, J. A., Futai, K., Vierling-Claassen, D., et al. (2012). A critical role for NMDA receptors in parvalbumin interneurons for gamma rhythm induction and behavior. Mol. Psychiatry 17, 537-548. doi: $10.1038 / \mathrm{mp} .2011 .31$

Castro-Alamancos, M. A. (2004). Absence of rapid sensory adaptation in neocortex during information processing states. Neuron 41, 455-464. doi: 10.1016/S08966273(03)00853-5

Chen, Y., Martinez-Conde, S., Macknik, S. L., Bereshpolova, Y., Swadlow, H. A., and Alonso, J.-M. (2008). Task difficulty modulates the activity of specific neuronal populations in primary visual cortex. Nat. Neurosci. 11, 974-982. doi: $10.1038 / \mathrm{nn} .2147$

Cho, R. Y., Konecky, R. O., and Carter, C. S. (2006). Impairments in frontal cortical gamma synchrony and cognitive control in schizophrenia. Proc. Natl. Acad. Sci. U.S.A. 103, 19878-19883. doi: 10.1073/pnas.0609440103

Dzirasa, K., Ramsey, A. J., Takahashi, D. Y., Stapleton, J., Potes, J. M., Williams, J. K., et al. (2009). Hyperdopaminergia and NMDA receptor hypofunction disrupt neural phase signaling. J. Neurosci. 29, 8215-8224. doi: 10.1523/JNEUROSCI.1773-09.2009

Ehrlichman, R. S., Gandal, M. J., Maxwell, C. R., Lazarewicz, M. T., Finkel, L. H., Contreras, D., et al. (2009). N-methyl-d-aspartic acid receptor antagonist-induced frequency oscillations in mice recreate pattern of electrophysiological deficits in schizophrenia. Neuroscience 158, 705-712. doi: 10.1016/j.neuroscience.2008.10.031

Ford, J. M., and Mathalon, D. H. (2008). Neural synchrony in schizophrenia. Schizophr. Bull. 34, 904-906. doi: 10.1093/schbul/sbn090

Galambos, R., Makeig, S., and Talmachoff, P. J. (1981). A 40-Hz auditory potential recorded from the human scalp. Proc. Natl. Acad. Sci. U.S.A. 78, 2643-2647. doi: 10.1073/pnas.78.4.2643

Gandal, M. J., Edgar, J. C., Klook, K., and Siegel, S. J. (2012a). Gamma synchrony: towards a translational biomarker for the treatment-resistant symptoms of schizophrenia. Neuropharmacology 62, 1504-1518. doi 10.1016/j.neuropharm.2011.02.007

Gandal, M. J., Sisti, J., Klook, K., Ortinski, P. I., Leitman, V., Liang, Y., et al. (2012b). GABAB-mediated rescue of altered excitatory-inhibitory balance, gamma synchrony and behavioral deficits following constitutive NMDAR-hypofunction. Transl. Psychiatry 2, e142. doi: 10.1038/tp.2012.69

Gentet, L. J., Avermann, M., Matyas, F., Staiger, J. F., and Petersen, C. C. H. (2010). Membrane potential dynamics of GABAergic neurons in the barrel cortex of behaving mice. Neuron 65, 422-435. doi: 10.1016/j.neuron.2010.01.006

Golomb, D., Donner, K., Shacham, L., Shlosberg, D., Amitai, Y., and Hansel, D. (2007). Mechanisms of firing patterns in fast-spiking cortical interneurons. PLoS Comput. Biol. 3:e156. doi: 10.1371/journal.pcbi.0030156

Haig, A. R., Gordon, E., De Pascalis, V., Meares, R. A., Bahramali, H., and Harris, A. (2000). Gamma activity in schizophrenia: evidence of impaired network binding? Clin. Neurophysiol. 111, 1461-1468. doi: 10.1016/S1388-2457(00)00347-3

Hakami, T., Jones, N. C., Tolmacheva, E. A., Gaudias, J., Chaumont, J., Salzberg, M., et al. (2009). NMDA receptor hypofunction leads to generalized and persistent aberrant gamma oscillations independent of hyperlocomotion and the state of consciousness. PLoS ONE 4:e6755. doi: 10.1371/journal.pone.0006755

Hamilton, L. S., Sohl-Dickstein, J., Huth, A. G., Carels, V. M., Deisseroth, K., and Bao, S. (2013). Optogenetic activation of an inhibitory network enhances feedforward functional connectivity in auditory cortex. Neuron 80, 1066-1076. doi: 10.1016/j.neuron.2013.08.017

Harris, K. D., and Thiele, A. (2011). Cortical state and attention. Nat. Rev. Neurosci. 12, 509-523. doi: $10.1038 / \mathrm{nrn} 3084$

Homayoun, H., and Moghaddam, B. (2007). NMDA receptor hypofunction produces opposite effects on prefrontal cortex interneurons and pyramidal neurons. J. Neurosci. 27, 11496-11500. doi: 10.1523/JNEUROSCI.2213-07.2007

Hong, L. E., Summerfelt, A., Buchanan, R. W., O’Donnell, P., Thaker, G. K., Weiler, M. A., et al. (2010). Gamma and delta neural oscillations and association with clinical symptoms under subanesthetic ketamine. Neuropsychopharmacology 35 , 632-640. doi: 10.1038/npp.2009.168
Jalili, M., Lavoie, S., Deppen, P., Meuli, R., Do, K. Q., Cuénod, M., et al. (2007). Dysconnection topography in schizophrenia revealed with state-space analysis of EEG. PLoS ONE 2:e1059. doi: 10.1371/journal.pone.0001059

Jiang, Z., Rompala, G. R., Zhang, S., Cowell, R. M., and Nakazawa, K. (2013). Social isolation exacerbates schizophrenia-like phenotypes via oxidative stress in cortical interneurons. Biol. Psychiatry 73, 1024-1034. doi: 10.1016/j.biopsych.2012.12.004

Kikuchi, M., Hashimoto, T., Nagasawa, T., Hirosawa, T., Minabe, Y., Yoshimura, M., et al. (2011). Frontal areas contribute to reduced global coordination of restingstate gamma activities in drug-naïve patients with schizophrenia. Schizophr. Res. 130, 187-194. doi: 10.1016/j.schres.2011.06.003

Kompus, K., Westerhausen, R., and Hugdahl, K. (2011). The "paradoxical" engagement of the primary auditory cortex in patients with auditory verbal hallucinations: a meta-analysis of functional neuroimaging studies. Neuropsychologia 49 , 3361-3369. doi: 10.1016/j.neuropsychologia.2011.08.010

Korotkova, T., Fuchs, E. C., Ponomarenko, A., von Engelhardt, J., and Monyer, H. (2010). NMDA receptor ablation on parvalbumin-positive interneurons impairs hippocampal synchrony, spatial representations, and working memory. Neuron 68, 557-569. doi: 10.1016/j.neuron.2010.09.017

Krishnan, G. P., Hetrick, W. P., Brenner, C. A., Shekhar, A., Steffen, A. N., and O'Donnell, B. F. (2009). Steady state and induced auditory gamma deficits in schizophrenia. Neuroimage 47, 1711-1719. doi: 10.1016/j.neuroimage.2009. 03.085

Kulikova, S. P., Tolmacheva, E. A., Anderson, P., Gaudias, J., Adams, B. E., Zheng, T., et al. (2012). Opposite effects of ketamine and deep brain stimulation on rat thalamocortical information processing. Eur. J. Neurosci. 36, 3407-3419. doi: 10.1111/j.1460-9568.2012.08263.x

Kwon, J. S., O’Donnell, B. F., Wallenstein, G. V., Greene, R. W., Hirayasu, Y., Nestor, P. G., et al. (1999). Gamma frequency-range abnormalities to auditory stimulation in schizophrenia. Arch. Gen. Psychiatry 56, 1001-1005. doi: 10.1001/archpsyc.56.11.1001

Lazic, S. E., and Essioux, L. (2013). Improving basic and translational science by accounting for litter-to-litter variation in animal models. BMC Neurosci. 14:37. doi: 10.1186/1471-2202-14-37

Lee, K.-H., Williams, L. M., Breakspear, M., and Gordon, E. (2003). Synchronous gamma activity: a review and contribution to an integrative neuroscience model of schizophrenia. Brain Res. Rev. 41, 57-78. doi: 10.1016/S0165-0173(02) 00220-5

Lee, S.-H., Wynn, J. K., Green, M. F., Kim, H., Lee, K.-J., Nam,. M., et al. (2006). Quantitative EEG and low resolution electromagnetic tomography (LORETA) imaging of patients with persistent auditory hallucinations. Schizophr. Res. 83, 111-119. doi: 10.1016/j.schres.2005.11.025

Leung, L. W. (1985). Spectral analysis of hippocampal EEG in the freely moving rat: effects of centrally active drugs and relations to evoked potentials. Electroencephalogr. Clin. Neurophysiol. 60, 65-77. doi: 10.1016/00134694(85) $90952-6$

Light, G. A., Hsu, J. L., Hsieh, M. H., Meyer-Gomes, K., Sprock, J., Swerdlow, N. R., et al. (2006). Gamma band oscillations reveal neural network cortical coherence dysfunction in schizophrenia patients. Biol. Psychiatry 60, 1231-1240. doi: 10.1016/j.biopsych.2006.03.055

Lisman, J. E., Coyle, J. T., Green, R. W., Javitt, D. C., Benes, F. M., Heckers, S., et al. (2008). Circuit-based framework for understanding neurotransmitter and risk gene interactions in schizophrenia. Trends Neurosci. 31, 234-242. doi: 10.1016/j.tins.2008.02.005

Llinás, R., and Ribary, U. (1993). Coherent 40-Hz oscillation characterizes dream state in humans. Proc. Natl. Acad. Sci. U.S.A. 90, 2078-2081. doi: 10.1073/pnas.90.5.2078

Ma, J., and Leung, L. S. (2000). Relation between hippocampal gamma waves and behavioral disturbances induced by phencyclidine and methamphetamine. Behav. Brain Res. 111, 1-11. doi: 10.1016/S0166-4328(00)00138-8

Ma, J., and Leung, L. S. (2007). The supramammillo-septal-hippocampal pathway mediates sensorimotor gating impairment and hyperlocomotion induced by MK-801 and ketamine in rats. Psychopharmacology (Berl). 191, 961-974. doi: $10.1007 / \mathrm{s} 00213-006-0667-\mathrm{x}$

Maharajh, K., Teale, P., Rojas, D. C., and Reite, M. L. (2010). Fluctuation of gammaband phase synchronization within the auditory cortex in schizophrenia. Clin. Neurophysiol. 121, 542-548. doi: 10.1016/j.clinph.2009.12.010

Maksimow, A., Särkelä, M., Långsjö, J. W., Salmi, E., Kaisti, K. K., Yli-Hankala, A., et al. (2006). Increase in high frequency EEG activity explains the poor 
performance of EEG spectral entropy monitor during S-ketamine anesthesia. Clin. Neurophysiol. 117, 1660-1668. doi: 10.1016/j.clinph.2006.05.011

McNally, J. M., McCarley, R. W., McKenna, J. T., Yanagawa, Y., and Brown, R. E. (2011). Complex receptor mediation of acute ketamine application on in vitro gamma oscillations in mouse prefrontal cortex: modeling gamma band oscillation abnormalities in schizophrenia. Neuroscience 199, 51-63. doi: 10.1016/j.neuroscience.2011.10.015

Mitchell, J. F., Sundberg, K. A., and Reynolds, J. H. (2007). Differential attentiondependent response modulation across cell classes in macaque visual area V4. Neuron 55, 131-141. doi: 10.1016/j.neuron.2007.06.018

Molina, L. A., Skelin, I., and Gruber, A. J. (2014). Acute NMDA receptor antagonism disrupts synchronization of action potential firing in rat prefrontal cortex. PLoS ONE 9:e85842. doi: 10.1371/journal.pone.0085842

Nakazawa, K., Zsiros, V., Jiang, Z., Nakao, K., Kolata, S., Zhang, S., et al. (2012). GABAergic interneuron origin of schizophrenia pathophysiology. Neuropharmacology 62, 1574-1583. doi: 10.1016/j.neuropharm.2011. 01.022

Niell, C. M., and Stryker, M. P. (2010). Modulation of visual responses by behavioral state in mouse visual cortex. Neuron 65, 472-479. doi: 10.1016/j.neuron. 2010.01.033

O’Donnell, B. F., Vohs, J. L., Krishnan, G. P., Rass, O., Hetrick, W. P., and Morzorati, S. L. (2013). The auditory steady-state response (ASSR): a translational biomarker for schizophrenia. Suppl. Clin. Neurophysiol. 62, 101-112. doi: 10.1016/B978-0-7020-5307-8.00006-5

Olney, J. W., and Farber, N. B. (1995). Glutamate receptor dysfunction and schizophrenia. Arch. Gen. Psychiatry 52, 998-1007. doi: 10.1001/archpsyc.1995. 03950240016004

Páleníček, T., Fujáková, M., Brunovskı, M., Balíková, M., Horáček, J., Gorman, I., et al. (2011). Electroencephalographic spectral and coherence analysis of ketamine in rats: correlation with behavioral effects and pharmacokinetics. Neuropsychobiology 63, 202-218. doi: 10.1159/000321803

Pastor, M. A., Artieda, J., Arbizu, J., Marti-Climent, J. M., Peñuelas, I., and Masdeu, J. C. (2002). Activation of human cerebral and cerebellar cortex by auditory stimulation at $40 \mathrm{~Hz}$. J. Neurosci. 22, 10501-10506.

Picton, T. W., John, M. S., Dimitrijevic, A., and Purcell, D. (2003). Human auditory steady-state responses. Int. J. Audiol. 42, 177-219. doi: 10.3109/149920203 09101316

Pike, F. G., Goddard, R. S., Suckling, J. M., Ganter, P., Kasthuri, N., and Paulsen, O. (2000). Distinct frequency preferences of different types of rat hippocampal neurones in response to oscillatory input currents. J. Physiol. 529, 205-213. doi: 10.1111/j.1469-7793.2000.00205.x

Pinault, D. (2008). N-methyl d-aspartate receptor antagonists ketamine and MK801 induce wake-related aberrant gamma oscillations in the rat neocortex. Biol. Psychiatry 63, 730-735. doi: 10.1016/j.biopsych.2007.10.006

Ropohl, A., Sperling, C. A. W., Elstner, S., Tomandl, B., Reulbach, U., Kaltenhìuser, M., et al. (2004). Cortical activity associated with auditory hallucinations. Neuroreport 15, 3-6. doi: 10.1097/00001756-200403010-00028

Rutter, L., Carver, F. W., Holroyd, T., Nadar, S. R., Mitchell-Francis, J., Apud, J., et al. (2009). Magnetoencephalographic gamma power reduction in patients with schizophrenia during resting condition. Hum. Brain Mapp. 30, 3254-3264. doi: 10.1002/hbm.20746

Sakata, S., and Harris, K. D. (2012). Laminar-dependent effects of cortical state on auditory cortical spontaneous activity. Front. Neural Circuits 6:109. doi: 10.3389/fncir.2012.00109

Santana, N., Troyano-Rodriguez, E., Mengod, G., Celada, P., and Artigas, F. (2011). Activation of thalamocortical networks by the N-methyl-D-aspartate receptor antagonist phencyclidine: reversal by clozapine. Biol. Psychiatry 69, 918-927. doi: 10.1016/j.biopsych.2010.10.030

Santarelli, R., Carraro, L., Conti, G., Capello, M., Plourde, G., and Arslan, E. (2003). Effects of isoflurane on auditory middle latency (MLRs) and steady-state (SSRs) responses recorded from the temporal cortex of the rat. Brain Res. 973, 240-251. doi: 10.1016/S0006-8993(03)02520-4

Silverstein, S. M., All, S. D., Thompson, J. L., Williams, L. M., Whitford, T. J., Nagy, M., et al. (2012). Absolute level of gamma synchrony is increased in firstepisode schizophrenia during face processing. J. Exp. Psychopathol. 3, 702-723. doi: $10.5127 /$ jep. 023311

Spencer, K. M. (2012). Baseline gamma power during auditory steadystate stimulation in schizophrenia. Front. Hum. Neurosci. 5:190. doi 10.3389/fnhum.2011.00190
Spencer, K. M., Nestor, P. G., Perlmutter, R., Niznikiewicz, M. A., Klump, M. C., Frumin, M., et al. (2004). Neural synchrony indexes disordered perception and cognition in schizophrenia. Proc. Natl. Acad. Sci. U.S.A. 101, 17288-17293. doi: 10.1073/pnas.0406074101

Spencer, K. M., Niznikiewicz, M. A., Nestor, P. G., Shenton, M. E., and McCarley, R. W. (2009). Left auditory cortex gamma synchronization and auditory hallucination symptoms in schizophrenia. BMC Neurosci. 10:85. doi: 10.1186/14712202-10-85

Spencer, K. M., Salisbury, D. F., Shenton, M. E., and McCarley, R. W. (2008). Gamma-band auditory steady-state responses are impaired in first episode psychosis. Biol. Psychiatry 64, 369-375. doi: 10.1016/j.biopsych.2008.02.021

Steriade, M., Nuñez, A., and Amzica, F. (1993). A novel slow ( $<1 \mathrm{~Hz})$ oscillation of neocortical neurons in vivo: depolarizing and hyperpolarizing components. J. Neurosci. 13, 3252-3265.

Steriade, M., Timofeev, I., and Grenier, F. (2001). Natural waking and sleep states: a view from inside neocortical neurons. J. Neurophysiol. 85, 1969-1985.

Suazo, V., Díez, Á., Martín, C., Ballesteros, A., Casado, P., Martín-Loeches, M., et al (2012). Elevated noise power in gamma band related to negative symptoms and memory deficit in schizophrenia. Prog. Neuropsychopharmacol. Biol. Psychiatry 38, 270-275. doi: 10.1016/j.pnpbp.2012.04.010

Tateno, T., Harsch, A., and Robinson, H. P. C. (2004). Threshold firing frequencycurrent relationships of neurons in rat somatosensory cortex: type 1 and type 2 dynamics. J. Neurophysiol. 92, 2283-2294. doi: 10.1152/jn.00109.2004

Teale, P., Collins, D., Maharaih, K., Rojas, D. C., Kronberg, E., and Reite, M. (2008). Cortical source estimates of gamma band amplitude and phase are different in schizophrenia. Neuroimage 42, 1481-1489. doi: 10.1016/j.neuroimage.2008. 06.020

Tsuchimoto, R., Kanba, S., Hirano, S., Oribe, N., Ueno, T., Hirano, Y., et al. (2011). Reduced high and low frequency gamma synchronization in patients with chronic schizophrenia. Schizophr. Res. 133, 99-105. doi: 10.1016/j.schres. 2011.07.020

Uhlhaas, P. J., and Singer, W. (2010). Abnormal neural oscillations and synchrony in schizophrenia. Nat. Rev. Neurosci. 11, 100-113. doi: 10.1038/nrn2774

Venables, N. C., Bernat, E. M., and Sponheim, S. R. (2009). Genetic and disorderspecific aspects of resting state EEG abnormalities in schizophrenia. Schizophr. Bull. 35, 826-839. doi: 10.1093/schbul/sbn021

Vierling-Claassen, D., Siekmeier, P., Stufflebeam, S., and Kopell, N. (2008). Modeling GABA alterations in schizophrenia: a link between impaired inhibition and altered gamma and beta range auditory entrainment. J. Neurophysiol. 99, 2656-2671. doi: 10.1152/jn.00870.2007

Winterer, G., Coppola, R., Sc, D., Goldberg, T. E., Ph, D., Egan, M. F., et al. (2004). Prefrontal broadband noise, working memory,and genetic risk for schizophrenia. Am. J. Psychiatry 161, 490-500. doi: 10.1176/appi.ajp.161.3.490

Woo, T.-U. W., Spencer, K., and McCarley, R. W. (2010). Gamma oscillation deficits and the onset and early progression of schizophrenia. Harv. Rev. Psychiatry 18, 173-189. doi: 10.3109/10673221003747609

Wood, J., Kim, Y., and Moghaddam, B. (2012). Disruption of prefrontal cortex large scale neuronal activity by different classes of psychotomimetic drugs. J. Neurosci. 32, 3022-3031. doi: 10.1523/JNEUROSCI.6377-11.2012

Yeragani, V. K., Cashmere, D., Miewald, J., Tancer, M., and Keshavan, M. S. (2006). Decreased coherence in higher frequency ranges (beta and gamma) between central and frontal EEG in patients with schizophrenia: a preliminary report. Psychiatry Res. 141, 53-60. doi: 10.1016/j.psychres.2005.07.016

Conflict of Interest Statement: The authors declare that the research was conducted in the absence of any commercial or financial relationships that could be construed as a potential conflict of interest.

Received: 26 April 2014; accepted: 02 June 2014; published online: 01 July 2014. Citation: Nakao K and Nakazawa K (2014) Brain state-dependent abnormal LFP activity in the auditory cortex of a schizophrenia mouse model. Front. Neurosci. 8:168. doi: 10.3389/fnins.2014.00168

This article was submitted to Auditory Cognitive Neuroscience, a section of the journal Frontiers in Neuroscience.

Copyright (๑) 2014 Nakao and Nakazawa. This is an open-access article distributed under the terms of the Creative Commons Attribution License (CC BY). The use, distribution or reproduction in other forums is permitted, provided the original author(s) or licensor are credited and that the original publication in this journal is cited, in accordance with accepted academic practice. No use, distribution or reproduction is permitted which does not comply with these terms. 